\title{
A (DES)OBRIGAÇÃO DE INFORMAÇÃO DA CONDIÇÃO DE TRANSEXUAL AO FUTURO CONJUGE OU COMPANHEIRO
}

\section{THE (NON)OBLIGATION OF INFORMATION OF THE TRANSEXUAL CONDITION TO THE FUTURE SPOUSE OR COMPANION}

${ }^{1}$ Barbara Bedin

\section{RESUMO}

O artigo trata à luz dos Direitos Humanos e Fundamentais e da Constituição Federal brasileira, a defesa do direito à intimidade do transexual sendo uma opção pessoal revelar sua condição ao futuro cônjuge ou companheiro. Através da técnica de pesquisa documental e bibliográfica são analisadas legislações nacionais e internacionais que tratam da dignidade da pessoa humana relacionadas ao direito de preservar a intimidade do transexual alterando o assento de nascimento para trocar o nome e o sexo, bem como a opção de informação de sua condição a terceiros. Conclui-se que a informação deve ficar restrita aos livros cartorários e ser disponibilizada a requerimento da parte ou por determinação judicial como a forma adequada de tratar o assunto e não violar a intimidade e a vida privada do transexual. Este, por sua vez, deve ser reconhecido pela forma como ele escolheu se apresentar socialmente.

Palavras Chaves: Direitos Humanos. Dignidade. Informação. Registro Civil. Transexual.

\begin{abstract}
The article deals with the Human and Fundamental Rights and the Brazilian Federal Constitution, the defense of the right to intimacy of the transsexual being a personal option to reveal its condition to the future spouse or companion. Through the technique of documentary and bibliographic research, national and international laws that deal with the dignity of the human person related to the right to preserve the intimacy of the transsexual are analyzed, changing the birth seat to alter name and gender, as well as the option of informing its condition to third parties. It is concluded that the information should be restricted to registry books and be made available at the request of the party or by court order as the proper way to treat the subject and not violate the privacy of the transsexual. Who, in turn, must be recognized by the way he chose to present himself socially.
\end{abstract}

Keywords: Human Rights. Dignity. Information. Civil Registry. Transsexual.

\footnotetext{
${ }^{1}$ Mestrado em Direito pela Universidade de Caxias do Sul, UCS - Rio Grande do Sul. Brasil.

E-mail: barbara@prelum.com.br
} 


\section{INTRODUÇÃO}

Este artigo trata do direito à intimidade de transexuais femininos ou masculinos a respeito de ter ou não obrigação de informar a sua condição para futuros cônjuges ou companheiros.

O indivíduo pode adequar o seu nome, prenome e sexo no registro civil para usufruir plenamente de seus direitos na forma como deseja ser reconhecido. E essas adequações perpassam, inevitavelmente, pela categoria jurídica dos direitos de personalidade e respeito a sua intimidade. No entanto, quando essas ações envolvem afetivo ou comercialmente terceiros discute-se a necessidade de informar a eles a condição de transexual.

Em um episódio da segunda temporada do seriado Orange Is The New Black disponível na Netflix Brasil, o assunto sobre o relacionamento afetivo e sexual com uma mulher transexual foi abordado de forma coerente. O seriado trata da história de uma mulher que está cumprindo pena em uma penitenciária feminina nos Estados Unidos.

Dois agentes penitenciários conversam a respeito de uma mulher transexual chamada Sofia que também cumpre pena naquele local. Em um dado momento, um deles demonstra atração por Sofia e faz comentários de cunho sexual ao colega referindo-se aquela detenta. O outro agente pergunta se ele realmente teria um envolvimento amoroso com Sofia, ao que lhe é respondido: "Eu não vivo de passado".

Esse artigo tem como objetivo, à luz dos Direitos Humanos e Fundamentais e da Constituição Federal brasileira defender o direito à intimidade e a uma opção pessoal de revelar a condição de transexual, apenas informando a impossibilidade de ter filhos através dos meios de reprodução natural.

A partir das bases lógicas da investigação, o método utilizado neste trabalho é dedutivo, uma vez que se baseia na lei geral para deduzir o caso concreto. Considerando ser impossível construir o artigo somente com a aplicação de um único método de forma pura, destaca-se o método que se sobressai entre os demais.

O procedimento analítico contribui para a organização das diversas fases da estruturação do artigo, através da pré-análise, exploração e tratamento do material. Além disso, como técnica utiliza-se a pesquisa documental (diretamente de leis e acórdãos) e a pesquisa bibliográfica.

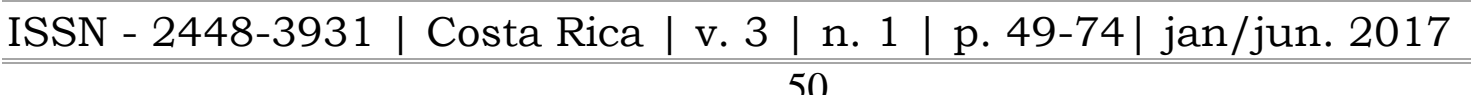


O Direito como fenômeno social deve proteger os valores que são considerados mais adequados para aquela realidade. Além disso, devem também observar situações de fato que precisam de regulamentação para ser por ele amparadas.

A primeira parte do artigo trata da contextualização da Constituição Federal brasileira (doravante Constituição) como a diretriz de maior valor na hierarquia das normas representando a construção de um ideal social defendido pelo Estado Democrático de Direito em nosso país. Na segunda parte, trata-se da internalização dos Direitos Humanos como Direitos fundamentais na Constituição, além da constitucionalização do Direito Privado. E por fim, argumenta-se com o objetivo de defender que a mulher transexual ou o homem transexual tem a opção de revelar ou não a sua condição ao cônjuge ou companheiro evitando, assim, a violação ao direito à intimidade.

\section{A dignidade da pessoa humana como conceito jurídico-normativo e o respeito à intimidade do transexual}

Os valores fundamentais da convivência entre os seres humanos deve ser o objetivo a ser alcançado pelas normas elaboradas em cada país. No Brasil, esse ideal é personificado pelo texto constitucional. Ele não é só a diretriz de maior valor na hierarquia das normas, mas representa a construção de um ideal social defendido pelo Estado Democrático de Direito. A Constituição manifesta-se Gomes ([2008] 2011, p. 99-102), é a síntese de um caminhar da humanidade, uma vez que aponta suas possibilidades atuais e futuras de construir uma convivência civilizada, além de trazer para o presente o resultado das vitórias e derrotas do Direito e dos direitos do passado. As vitórias civilizadoras estão retratadas nos princípios e direitos fundamentais e devem ser reconhecidos de forma consciente pelas autoridades e população, para que a normatividade da Constituição se concretize e tenha sentido. A compreensão não é restrita ao texto constitucional, mas considera toda a ordem jurídica à luz dos princípios fundamentais ali positivados.

Os valores básicos que sustentam a ordem jurídica são representados na Constituição por seus princípios fundamentais, que podem ser conflitivos em algumas situações, mas que geram uma unidade axiológica representativa da sociedade. Concluise, portanto, que estando codificada ou não, a normativa a ser seguida pelo julgador é $\frac{\text { ISSN - 2448-3931| Costa Rica | v. } 3 \text { | n. } 1 \text { | p. 49-74 | jan/jun. } 2017}{51}$ 
aquela estabelecida na Carta Magna, por representar a construção dos ideais relevantes para nossa sociedade. Da mesma forma, a construção do entendimento sobre o respeito a intimidade do transexual deve pautar-se pelas normas ${ }^{2}$ constitucionais, bem como com pelos princípios de valoração a ela subjacentes com o modelo social da Constituição.

Em que pese estar qualificada como valor fundamental da ordem jurídica, não só da Constituição brasileira, mas de todas aquelas que pretendem alcançar um Estado Democrático, o termo dignidade da pessoa humana, tem contornos vagos e imprecisos e é de difícil conceituação, consoante esclarece Sarlet (2012, p. 48-55). Esse conceito, como muitos outros do Direito, caracteriza-se por ser ambíguo e poroso, além de apresentar-se, necessariamente, com uma natureza polissêmica. É um conceito em permanente construção e desenvolvimento, mas em que foram estabelecidas, ao longo do tempo, algumas diretrizes fundamentais para defini-lo e concretizá-lo.

A dignidade humana é um atributo intrínseco à pessoa humana, sem, no entanto caracterizar um atributo físico que é inerente à sua natureza. Além disso, é irrenunciável e inalienável, sem se cogitar a possibilidade de lhe ser concedida através de uma pretensão, uma vez que é atribuída a cada ser humano como algo que lhe é inerente. Deve ser reconhecida, respeitada, promovida e protegida, porém, não pode ser criada, concedida ou retirada, embora possa ser violada.

A tutela da pessoa humana está prevista no rol dos Princípios Fundamentais do art. $1^{\circ}$, inciso III, da Constituição, sendo considerada uma cláusula geral e esse mandamento também é utilizado como fundamento para a constitucionalização do direito privado. A dignidade humana, portanto, é respeitada e protegida, contudo, não é uma criação constitucional, explica Moraes (2010, p.119), mas um princípio fundamental consagrado pela Constituição por causa de sua eminência e considerada o valor supremo de alicerce da ordem jurídica democrática.

Há quem argumente, destaca Sarlet (2012, p. 57), que a dignidade da pessoa humana seja dotada de um sentido cultural advindo do trabalho de diversas gerações e da humanidade em seu todo. Por esse motivo, existe a interação entre as dimensões natural e cultural da dignidade da pessoa humana, refutando-se a ideia de que sua dimensão ontológica se equipare a uma dimensão biológica. Sarlet refere que a ideia de dignidade da pessoa humana contém elementos histórico-culturais, a qual também foi

\footnotetext{
${ }^{2}$ Para fins deste artigo, adota-se o entendimento de que as normas são reconhecidas como o conjunto de princípios e regras aplicadas ao Direito.
}

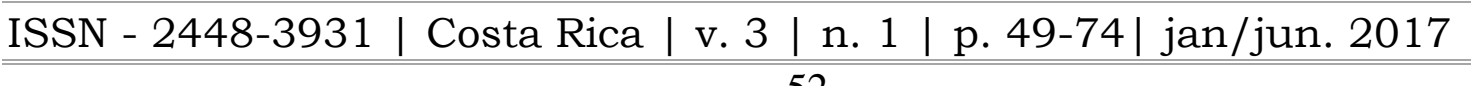


recepcionada em outras ordens constitucionais, como o Tribunal Constitucional Federal da Alemanha e o Tribunal Constitucional de Portugal. Deste último, refere o acórdão 90-105-2 que se ajusta perfeitamente a essa questão:

\begin{abstract}
[...] a ideia de «dignidade da pessoa humana», no seu conteúdo concreto nas exigências ou corolários em que se desmultiplica —, não é algo de puramente apriorístico [...] e ou a-histórico, mas algo que justamente se vai fazendo (e que vai progredindo) na história, assumindo, assim, uma dimensão eminentemente «cultural». Para dizer ainda com Vieira de Andrade: «o valor da dignidade da pessoa humana [...] corresponde a uma potencialidade característica do ser humano, que se vai actualizando nas ordens jurídicas concretas». $[\ldots]$

É que, se o conteúdo da ideia de dignidade da pessoa humana é algo que necessariamente tem de concretizar-se histórico-culturalmente, já se vê que no Estado moderno [...] há-de caber primacialmente ao legislador essa concretização: especialmente vocacionado, no quadro dos diferentes órgãos de soberania, para a «criação» e a «dinamização» da ordem jurídica, e democraticamente legitimado para tanto, é ao legislador que fica, por isso, confiada, em primeira linha, a tarefa ou o encargo de, em cada momento histórico, «ler», traduzir e verter no correspondente ordenamento aquilo que nesse momento são as decorrências, implicações ou exigências dos princípios «abertos» da Constituição (tal como, justamente, o princípio da «dignidade da pessoa humana»).
\end{abstract}

Sendo assim, somente no contexto de uso é que o sentido de dignidade da pessoa humana será delineado. A sociedade clama por justiça para protegê-la de suas angústias e que, de acordo com Bittar (2010, p. 261), são representadas pela miséria, injustiça, sofrimento, exploração, desvio, deturpação, corrupção, degradação, entre outros. Essa demanda por justiça está depositada na expressão dignidade da pessoa humana, que é fundamental, nas palavras de Bittar (2012, p. 261), "para a cultura dos direitos, esta que se dedica exatamente a identificar e a proteger valores que sejam construídos historicamente a partir das próprias mazelas do trato comum das coisas e da vida social."

A dignidade tem estreita ligação com a liberdade de autodeterminação ${ }^{3}$, não sendo noções que se equiparam, mas, de acordo com Sarlet (2009, p. 15-43), se ligam intrinsecamente, uma vez que uma das principais exigências da dignidade humana é a garantia de direitos de liberdade. diversas considerações Diversas considerações são apresentadas por Sarlet (2012, p. 59-70) até propor um conceito de dignidade da pessoa humana. Refere a dignidade através da perspectiva de limite e tarefa, mantendo-se uma dupla dimensão: a primeira, como expressão da autonomia da pessoa humana

${ }^{3}$ Matriz kantiana centrada na autonomia e no direito de autodeterminação de cada pessoa.

ISSN - 2448-3931| Costa Rica | v. 3 | n. 1 | p. 49-74 | jan/jun. 2017 
(autodeterminação das decisões essenciais referentes à própria existência); e a segunda, como necessidade de sua proteção (assistência). Ainda, a partir de Dworkin, pressupõe a conexão entre uma voz ativa e outra passiva, em que mesmo aquele que já perdeu a consciência de sua dignidade, ainda assim deve ser tratado. Tal argumento reporta-se à obra de Kant, de forma que nenhum homem pode ser usado como mero instrumento para a realização dos fins alheios, ou seja, não pode ser tratado como objeto.

Nessa perspectiva, em muitas situações, uma violação da dignidade é identificada por meio do objetivo da conduta (intenção de "coisificar" o outro). Os indivíduos são sujeitos do discurso e da ação e, por esse motivo, de acordo com Moraes (2010, p. 120),

se a humanidade das pessoas reside no fato de elas serem racionais, dotadas de livre arbítrio e de capacidade para interagir com os outros e com a natureza...[...] será 'desumano', isto é, contrário à dignidade humana, tudo aquilo que puder reduzir a pessoa (o sujeito de direitos) à condição de objeto.

A dignidade da pessoa é violada sempre no caso concreto, considerando-a a partir de determinada ou determinadas pessoas. Dessa forma, não é possível desrespeitar a dignidade da pessoa em abstrato, uma vez que o objetivo da dignidade humana é o indivíduo e não toda a humanidade.

A dignidade tem caráter intersubjetivo e relacional (Kant), destaca Sarlet (2012, p. 59-70), existindo um dever de respeito nos limites da comunidade de seres humanos. A perspectiva intersubjetiva acarreta uma obrigação geral de respeito à pessoa, justamente pelo seu valor intrínseco como tal, representada por um conjunto de direitos e deveres correlativos (bens indispensáveis ao indivíduo). As pessoas não podem ser tratadas de forma indigna; todavia, essa indignidade deve ser analisada de acordo com as convenções sociais, que variam em conformidade com a época e o lugar. Pode-se dizer, então, que a dignidade é dialógica, posto que se eu me vejo no outro, devo considerá-lo nos limites do que penso que é digno e como desejo que o outro respeite a minha dignidade, através da construção histórico-cultural da época em que estou inserida.

Diante de todas essas considerações, Sarlet (2012, p. 72-73) conclui pela impossibilidade de reduzir o conceito de dignidade da pessoa humana a uma fórmula genérica e abstrata, que seja necessária uma definição que alcance seu sentido e operacionalidade no caso concreto, com vistas a garantir um certo grau de estabilidade e 
segurança jurídica, bem como para evitar que se justifique o contrário da dignidade. E, assim, é feita a seguinte proposta conceitual da dignidade da pessoa humana, que deve sempre ser testada, considerando a relação entre a dignidade da pessoa humana e os direitos fundamentais:

[...] a qualidade intrínseca e distintiva reconhecida em cada ser humano que o faz merecedor do mesmo respeito e consideração por parte do Estado e da comunidade, implicando, nesse sentido, um complexo de direitos e deveres fundamentais que assegurem a pessoa tanto contra todo e qualquer ato de cunho degradante e desumano, como venham lhe garantir as condições existenciais mínimas para uma vida saudável, além de propiciar e promover sua participação ativa e co-responsável nos destinos da própria existência e da vida em comunhão com os demais seres humanos, mediante o devido respeito aos demais seres que integram a rede da vida. (SARLET, 2012, p. 73, grifos do autor).

A partir desse conceito, deve-se verificar como a dignidade da pessoa humana se transmuta para o ordenamento jurídico-constitucional brasileiro. Como já mencionado anteriormente, a dignidade da pessoa humana está positivada no texto constitucional e, nesse sentido, adota-se o posicionamento de Sarlet $(2012 \text {, p. } 81)^{4}$ de que o direito positivo é "um sistema de normas ${ }^{5}$ integrado tanto por regras como por princípios expressos e implícitos, ambas as categorias, por sua vez, impregnada de valores [...]”. E conhecer a importância que foi dada à dignidade da pessoa humana na Constituição Federal, indicará, no âmbito jurídico, sua importância e vigor na qualidade de norma fundamental.

Sinale-se, por oportuno, que o direito à dignidade refere-se ao seu reconhecimento, respeito, promoção e desenvolvimento, não se revestindo em direito fundamental. Isso significa dizer, explica Sarlet (2012, p. 84-85), que a dignidade da pessoa como princípio jurídico pode servir de base a posições jurídico-subjetivas, ou seja, normas definidoras de direitos e garantias, e, também, de deveres fundamentais. Não se reconhece um direito fundamental à dignidade da pessoa humana, mas um direito à existência digna.

Destaca-se, também, de acordo com Sarlet (2012, p. 86-87), que a dignidade da pessoa humana (como princípio fundamental) em relação aos direitos e deveres

\footnotetext{
${ }^{4}$ Para fins deste artigo, adota-se o entendimento de que as normas são reconhecidas como o conjunto de princípios e regras aplicadas ao Direito.

5 As regras contêm prescrições imperativas de conduta, enquanto os princípios são mandados de otimização, ordenando que algo seja realizado, na maior medida possível, e considerando as possibilidades fáticas e jurídicas existentes. (Sarlet, 2012, p. 87).
}

$\frac{\underline{\text { ISSN }-2448-3931 \mid \text { Costa Rica | v. } 3 \text { | n. } 1 \text { | p. 49-74 | jan/jun. } 2017}}{55}$


fundamentais possui uma dupla dimensão jurídica: a objetiva e a subjetiva, e que guarda relação com os valores fundamentais de uma comunidade. E, nessa direção, os princípios e direitos fundamentais são, de acordo com Sarlet (2012, p. 86):

[...] expressão jurídico-constitucional (mediante a incorporação ao direito positivo, na condição de direito objetivo) de uma determinada ordem de valores comunitária, não podendo ser reduzido a direitos (posições subjetivas) individuais. Também por esta razão (mas não exclusivamente), é que a dignidade da pessoa, do indivíduo, é sempre a dignidade do indivíduo socialmente situado e responsável [...].

O reconhecimento da dignidade da pessoa humana não se expressa como um princípio absoluto que aparenta essa certeza, por dois motivos explica Sarlet (2012, p. 89): o primeiro, porque a dignidade advém de duas normas, uma regra e um princípio; e, em segundo lugar, pelo fato de que, em muitas situações, o princípio da dignidade prevalece mediante todos os demais princípios. A dignidade da pessoa, por sua vez, como um princípio, deve harmonizar-se à igual dignidade de todos os seres humanos, ou seja, ter sua parcela de relatividade.

$\mathrm{Na}$ condição de princípio, Sarlet (2012, p. 87) explicita que a dignidade da pessoa desempenha "[...] um mandado de otimização, ordenando algo (no caso, a proteção e promoção da dignidade da pessoa) que deve ser realizado na maior medida possível, considerando as possibilidades fáticas e jurídicas existentes". Na condição de regra, é percebida a partir da constatação de que, nos casos em que a norma da dignidade humana é relevante, questiona-se, tão somente, se ela foi violada, ou não (e não se ela prevalece sobre outras normas).

As obras jurídicas, conforme destaca Sarlet (2012, p. 92-94), consideram que a dignidade da pessoa humana desempenha o papel de imprimir à ordem constitucional: (a) uma unidade de sentido, por atuar como elemento de integração e critério hermenêutico, a partir do momento em que serve de parâmetro para aplicação, interpretação e integração não apenas dos direitos fundamentais e das demais normas constitucionais, mas de todo o ordenamento jurídico; e (b) legitimidade, por dizer com a razão de ser do próprio poder estatal.

A relação entre a dignidade e os direitos fundamentais de acordo com Sarlet (2012, p. 124), com base em Geddert-Steinacher, é uma relação sui generis, visto que, em muitos casos, a dignidade da pessoa assume a função de elemento e medida dos 
direitos fundamentais, simultaneamente. Isso significa dizer que, em regra, a violação de um direito fundamental estará vinculada à dignidade da pessoa.

A proposta de "pragmatização" do conceito de dignidade da pessoa humana, aproveitada quando é possível obter um resultado positivo em termos de clareza, a partir de uma adequada identificação das esferas específicas de proteção dos direitos fundamentais diversos e individualmente considerados, é reconhecida por Sarlet (2012, p. 125). Em maior parte, a cláusula geral da dignidade da pessoa humana se concretiza, em termos técnico-jurídicos, por meio dos direitos fundamentais em espécie. Por outro lado, a violação da dignidade, através de novas ofensas e ameaças, autoriza a proteção de direitos fundamentais que, em princípio, não estão explícitos na Constituição.

Os princípios jurídicos que representam o núcleo referencial da dignidade, de acordo com Moraes (2010, p. 120-139) são a igualdade, a integridade física e moral (psicofísica), a liberdade e a solidariedade. A forma de violação primeira do direito à igualdade corresponde à prática de atos discriminatórios ao fazer diferença entre sujeitos da mesma categoria, sem fundamentação jurídica (ratio). Modernamente, considera-se que a esse princípio deve-se acrescentar o princípio da diversidade, ou seja, o respeito à especificidade de cada cultura. A violação ao princípio de proteção à integridade psicofísica está representada, tradicionalmente, pelo direito a não tortura e direito a algumas garantias penais, além do direito à existência digna. Já no Direito Civil, esse princípio garante inúmeros direitos de personalidade (vida, nome, imagem, honra, privacidade, corpo, identidade pessoal e o direito à saúde).

A liberdade, atualmente, é vista sob a perspectiva de privacidade, de intimidade, de livre exercício da vida privada. São exemplos de violação da dignidade da pessoa humana, em razão da lesão à liberdade, a revista íntima e a exigência de exame toxicológico aos empregados, a exigência de se submeter ao bafômetro, a impossibilidade de receber tratamento médico por causas religiosas, a incapacidade de controle de dados pessoais, a restrição à manifestação de pensamento ou crítica, a prisão ilegal, o cárcere privado, entre outros. A liberdade individual deve sempre ser considerada à luz da solidariedade social. A solidariedade social, como valor (dignidade social), origina-se da consciência racional dos interesses em comum, implicando a cada membro 'não fazer aos outro o que não gostaria que lhe fizesse', como uma obrigação moral.

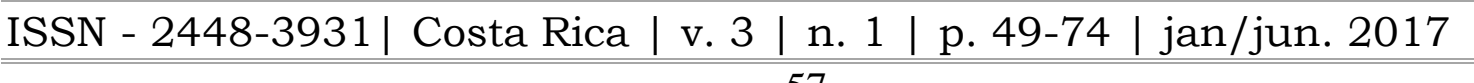


Trata-se de um conjunto de elementos que tem por objetivo garantir uma existência digna, comum a todos, em uma sociedade que se desenvolva como livre e justa. Viola-se esse princípio nas lesões que tenham no grupo a sua ocasião de acontecer: danos sofridos no contexto familiar, nas mais diversas modalidades (lesão a capacidade procriadora ou sexual do cônjuge, descumprimento de pensão alimentícia, não reconhecimento voluntário de paternidade); danos causados aos sócios minoritários; descumprimento dos deveres fundados na boa-fé.

Os exemplos apresentados não são absolutos e, de acordo com Moraes (2010, p. 139), "todas as lesões que podem ser reconduzidas a, pelo menos um desses quatro princípios, são graves o bastante para gerar a reparação por dano moral", ou seja, a uma responsabilidade civil. O desrespeito ao desejo de não revelar a condição do transexual pode ser enquadrado como uma violação da dignidade da pessoa humana a uma espécie de direito fundamental, em razão da lesão ao princípio da solidariedade social implicar o dever de respeito ao outro, como eu gostaria que ele me respeitasse.

Em seguida, relaciona-se a dignidade da pessoa humana aos direitos fundamentais direcionados ao ambiente constitucional brasileiro.

\section{Os direitos fundamentais na Constituição brasileira}

A origem dos direitos fundamentais baseia-se na garantia de liberdade dos indivíduos frente ao Estado. Esse parâmetro, bem como a sua eficácia, ampliou-se no decorrer do processo histórico, incluindo-se a relação entre os indivíduos no mesmo nível de igualdade, os quais, assim, nas palavras de Sarlet (2010a, p. 378), “expressam uma ordem de valores objetivada na e pela Constituição". O que dá sentido, valor e concordância prática ao sistema de direitos fundamentais é a Constituição que, em que pese ter um cunho compromissário, repousa na dignidade da pessoa humana, esclarece Sarlet (2012, p. 91), ou seja, "na concepção que faz da pessoa fundamento e fim da sociedade e do Estado [...]".

Os direitos fundamentais, de acordo com a doutrina germânica, são direitos humanos positivados nas Constituições, nas leis e nos tratados internacionais e também são chamados de direitos fundamentais típicos. Nesta lógica, os direitos humanos que não estão manifestados de forma expressa não podem ser exigidos em juízo. No entanto, por não existir a pretensão (por não estarem positivados e não poderem ser exigidos judicialmente ou extrajudicialmente), não significa que não exista o direito 
subjetivo que é a pertinência de um bem da vida a alguém. (COMPARATO, 2010, p. 70-73).

Pode-se dizer que a dignidade está entrelaçada em diversas áreas do espaço social e é tomada como referência por elas, da forma como ilustra Sarlet (2012, p. 92 93) ao mencionar que a dignidade tem uma função normativa, porém não jurídica ao ser usada como parâmetro sociocultural no processo decisório político jurídico em que se afirma, por exemplo, que toda violação da dignidade é injusta. Ou quando é tomada como um conceito referencial sobre o que cada um entende o que é e sua forma de promoção e/ou proteção, mesmo que seja entre particulares.

A dignidade, portanto, possui duas naturezas: a primeira, como fonte dos direitos fundamentais; e a segunda, como conteúdo desses direitos. As duas funções são compatíveis entre si, sendo que os tribunais brasileiros, cada vez mais, utilizam-se da dignidade da pessoa humana como critério hermenêutico, isto é, como fundamento para a solução de controvérsias, nas mais diversas áreas jurídicas. No entanto, afirma Sarlet (2012, p. 96), os julgadores desvalorizam e fragilizam a aplicação do princípio da dignidade humana quando não demonstram a noção subjacente utilizada, bem como não indicam qual conduta é ou não considerada ofensiva à dignidade.

Os Direitos e Garantias Fundamentais ${ }^{6}$ estão expressos na Constituição, no Título II e abrangem o Capítulo I (Dos Direitos e Deveres Individuais e Coletivos), o Capítulo II (Dos Direitos Sociais), o Capítulo III (Da Nacionalidade), o Capítulo IV (Dos Direitos Políticos) e o Capítulo V (Dos Partidos Políticos). Em que pese algumas críticas a respeito de serem ou não os direitos sociais considerados como direitos fundamentais, a autora acompanha o entendimento majoritário da obra brasileira de que todos os capítulos do Título II são direitos fundamentais e, ainda, outros previstos ao longo do texto constitucional, matérias de Direitos Humanos expressas em tratados internacionais e direitos fundamentais implícitos subentendidos naqueles manifestadamente positivados. E esse posicionamento, explica Sarlet (2010, p. 17):

[...] não significa necessariamente um tratamento jurídico equivalente de todos os direitos fundamentais (especialmente no que concerne à sua proteção, eficácia e efetividade) [...] o que não equivale a dizer que o regime jurídico dos direitos fundamentais não seja substancialmente o mesmo.

\footnotetext{
${ }^{6}$ A Constituição ainda distingue, de forma expressa, o que são os direitos humanos (posições jurídicas de qualquer pessoa humana, reconhecidas e tuteladas pelo direito positivo internacional) e os direitos fundamentais (positivados expressa ou implicitamente no âmbito do direito constitucional). (SARLET, 2010, p. 17).
}

ISSN - 2448-3931| Costa Rica | v. 3 | n. 1 | p. 49-74 | jan/jun. 2017 
Ademais, os direitos fundamentais formam, em nosso ordenamento jurídicoconstitucional, um grupo de posições jurídicas complexas e heterogêneas e, em função de sua multifuncionalidade, são reconhecidos através de sua (a) dimensão negativa como direito de defesa e (b) positiva, como direito à prestação. Esse último (b) dividese, ainda, em dois subgrupos: (b1) o dos direitos a prestações em sentido amplo (englobando os direitos de proteção e os direitos à participação na organização e no procedimento) e (b2) o dos direitos a prestações em sentido estrito (direitos a prestações materiais sociais). Essa classificação está alicerçada na posição jurídico-subjetiva reconhecida ao titular de direitos fundamentais ${ }^{7}$, a partir da defesa contra interferências inapropriadas, ou a exigência de atuação positiva do Estado e da sociedade.

No geral, os direitos fundamentais sociais e a dignidade da pessoa relacionam-se a um diversificado complexo de posições jurídico-subjetivas negativas (defensivas) e positivas (prestacionais), explícitas ou implícitas. Quando é objeto de análise, deve receber um olhar atento, porque se deve pautar pelos valores que são considerados relevantes naquela época e, ainda, considerar a organização política e econômica do Estado.

Permeando esse ambiente constitucional está os Direitos Humanos com o objetivo de, segundo Moraes e Santin (2010, p. 424) “concretizar o maior fundamento do Estado Democrático de Direito brasileiro: o principio da dignidade da pessoa humana".

A partir de toda essa argumentação Comparato (2010, p. 74) explica que em um eventual conflito entre normas internas e o direito internacional, o entendimento predominante é considerar as normas internacionais de direito humanos acima das legislações de cada Estado por representarem uma consciência ética universal e a proteção da dignidade humana é a finalidade última e razão de todo ordenamento jurídico.

No próximo tópico, aborda-se a vinculação dos direitos fundamentais entre particulares e a sua influência no respeito ao direito à intimidade e a vida privada.

\section{Os direitos fundamentais e o direito privado}

\footnotetext{
${ }^{7}$ Esse critério foi desenvolvido principalmente por Jellinek, aperfeiçoado por Robert Alexy e inserido por Gomes Canotilho e Vieira de Andrade no direito constitucional português, bem como para o direito constitucional brasileiro por Ingo Sarlet, dentre outros e pode ser consultado na obra desses autores para um aprofundamento no assunto.
}

$\frac{\text { ISSN - 2448-3931 | Costa Rica | v. } 3 \text { | n. } 1 \text { | p. 49-74| jan/jun. } 2017}{60}$


O Direito, em sua forma tradicional, é dividido em duas grandes áreas: o Direito Público e o Direito Privado, com a justificativa de organização sistemática e facilidade prática $^{8}$. De uma forma simplista, pode-se dizer que o Direito Público reúne as disciplinas que regem as relações em que o Estado ${ }^{9}$ é parte, enquanto no Direito Privado, agregam-se as disciplinas que regem, exclusivamente, as relações entre os particulares.

O Direito Privado, que inclui o Direito Civil, pressupõe um espaço de não intervenção do Estado e que, conforme explicam Fachin e Ruzyk (2010, p. 98), são deveres de omissão por parte do Estado, também chamados de liberdade negativa: "É do exame dessas liberdades que se revela a constituição da clivagem pública e privada, uma vez que é precisamente na constituição dos direitos subjetivos que estabelecerão os limites de atuação do Estado."

Em nosso país, as transformações histórico-culturais do século XX culminaram com a promulgação da Constituição, protegendo as garantias fundamentais, os direitos humanos, a ordem econômica vigente e a liberdade. A dignidade da pessoa passa a ser considerado o valor mais intenso, o princípio que é considerado fonte dos direitos fundamentais (e direitos humanos também), e como conteúdo desses direitos, é o fundamento de todo o ordenamento jurídico. E, sendo o Direito Privado parte desse todo a dignidade da pessoa também é um valor a ser protegido naquela esfera. A dignidade humana, de acordo com Nipperdey (2011, p. 52), realiza-se no ordenamento jurídico:

[...] quando ela assegura à pessoa uma esfera, na qual ela pode atuar como ser independente e moralmente autorresponsável, na qual ela nem é submetida a pretensão de poder de uma outra pessoa, nem é transformada em mero meio de uma finalidade comunitária, mas é pessoa autorresponsável livre.

$\mathrm{O}$ artigo $5^{\circ}$ da Constituição determina que todos são iguais perante a lei sem distinção de qualquer natureza, garantindo a inviolabilidade do direito à vida, à liberdade, à igualdade, à segurança e à propriedade, além de serem elencadas várias outras situações que são protegidas - como a livre manifestação de pensamento, a inviolabilidade do sigilo da correspondência, a residência, a intimidade, a vida privada,

\footnotetext{
${ }^{8}$ Referência ao Direito e sistema jurídico brasileiro.

${ }^{9}$ Com exceção do art. 173 da Constituição, em que o Estado pratica atividades econômicas e é regido pelo Direito Privado.
}

ISSN - 2448-3931| Costa Rica | v. 3 | n. 1 | p. 49-74 | jan/jun. 2017 
a honra e a imagem das pessoas, entre tantos direitos fundamentais que são imperativos no Direito Privado. Dessa forma, o indivíduo está vinculado à comunidade, mas sem tocar em seu valor próprio. O Estado de Direito Social é o resultado da vinculação do particular à comunidade e que tem como resultado imediato, de acordo com Nipperdey (2011, p. 54), "limites imediatos à liberdade individual".

Os direitos fundamentais interferem na esfera privada de diversas formas: primeiro, garantem ao particular um espaço livre do Estado; segundo, o Estado intervém/protege institutos como casamento, livre comércio, direito à propriedade e à herança. Nesses casos, os particulares têm limitações porque não podem contrariar as garantias daqueles institutos e qualquer outro protegido constitucionalmente.

E, em terceiro lugar, alguns direitos fundamentais abrangem todo o ordenamento jurídico e, por tal motivo, tem aplicação imediata aos particulares. São direitos fundamentais que se dirigem ao Estado, mas, em função de seus efeitos plenos, Nipperdey (2011, p. 59) diz tratar-se do "efeito normativo imediato de determinações de direitos fundamentais particulares em sua qualidade de direito constitucional objetivo, vinculativo que anulou, modificou, complementou ou criou de novo determinações de direito privado".

Nessa direção, Facchini Neto (2010, p. 56-58) evidencia que a chamada constitucionalização do Direito Privado manifesta-se por dois caminhos: (a) pela influência das normas constitucionais, via concretização legislativa e/ou judicial sobre as normas de Direito Privado e as relações entre particulares; e (b) por meio de institutos originalmente de Direito Privado previstos na Constituição que irão influenciar tal Direito. Adotando a tese de que a eficácia dos direitos fundamentais é imediata entre particulares, ou seja, é uma eficácia direta prima facie, registra-se que, apesar da influência da obra estrangeira ${ }^{10}$, é necessário considerar as condições peculiares do nosso contexto sociojurídico, nos termos do que esclarece Sarlet (2007, p. 132-133):

${ }^{10}$ A influência da doutrina estrangeira sobre a construção dos direitos fundamentais brasileiros pode ser
consultada em: SARLET, Ingo Wolfgang. A influência dos direitos fundamentais no direito privado: o
caso brasileiro. In: MONTEIRO, António Pinto; NEUNER, Jörg; SARLET, Ingo Wolfgang (Org.).
Direitos fundamentais e direito privado: uma perspectiva de direito comparado. Coimbra: Almedina,
2007 . p.111-144. E em FACCHINI NETO, Eugênio. Reflexões histórico-evolutivas sobre a
constitucionalização do direito privado. In: SARLET, Ingo Wolfgang (Org). Constituição, direitos
fundamentais e direito privado. 3 . ed. rev. e ampl. Porto Alegre: Livraria do Advogado, p. 37-75, 2010 .

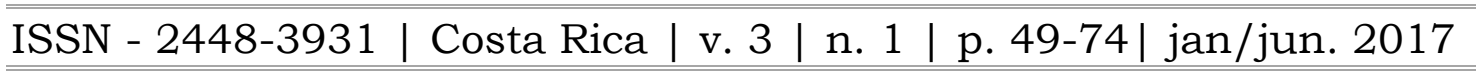


[...] somente as circunstâncias de cada caso concreto, as peculiaridades de cada direito fundamental e do seu âmbito de proteção, as disposições legais vigentes e a observância dos métodos de interpretação e solução de conflitos entre direitos fundamentais (como é o caso da proporcionalidade e da concordância prática) podem assegurar uma solução constitucionalmente adequada $[\ldots]$.

$\mathrm{O}$ discurso constitucional prioriza os fenômenos jurídicos relacionados às questões existenciais em detrimento das relações patrimoniais e a norma civilista tem que se adaptar a esse novo olhar. A constitucionalização do Direito Civil deve ser entendida mais como uma questão valorativa do que, propriamente, uma questão de hierarquia, em que a Constituição é norma superior. O significado mais profundo da constitucionalização do Direito Civil, de acordo com Moraes (2010, p. 112), é reconhecer que os valores expressos pelo legislador constituinte devem informar o sistema jurídico como um todo. E referidos valores originam-se da cultura, isto é, da consciência social, do ideal ético e da noção de justiça inseridos na sociedade.

A observância dos valores conformadores da Constituição, por óbvio, deve ser aplicada a vida privada das pessoas prevista no art. 21, do Código Civil brasileiro: “A vida privada da pessoa natural é inviolável, e o juiz, a requerimento do interessado, adotará as providências necessárias para impedir ou fazer cessar ato contrário a esta norma".

Dessa forma, as normas de direitos fundamentais produzem efeito imediato na relação entre os particulares, ou seja, entre cidadão-cidadão. Quando o tribunal se deparar com um caso de afronta a um direito fundamental atribuído a um particular, ele deverá analisar o que é mais importante proteger. Como ocorre a aplicação no caso concreto, e em que medida, é uma questão de interpretação e organização dos direitos fundamentais envolvidos, de tal forma que se considere a ligação temporal da Constituição com os contextos político e social que lhe dão suporte.

\section{O reconhecimento da violação ao direito a vida privada e a intimidade}

A proteção aos direitos da vida privada não iniciou no direito privado, mas sim no âmbito constitucional, conforme explicita Mello (2006, p. 76): "Foi no âmbito do direito constitucional que ela [proteção da personalidade pelo sistema jurídico] se originou, com a tutela dos direitos fundamentais, nas constituições modernas." Ainda de acordo com o autor (MELLO, 2006, p. 76-77) na Declaração da Independência dos ISSN - 2448-3931| Costa Rica | v. 3 | n. 1 | p. 49-74 | jan/jun. 2017 
Estados Unidos da América, em 1776 já estava presente a preocupação em proteger os atributos intrínsecos da pessoa humana.

Após a Segunda Guerra, as concepções culturais de homem e sociedade tiveram que ser repensadas surgindo, então, a concepção de dignidade da pessoa humana que resumia a proteção da personalidade humana através de direitos subjetivos constitucionalmente protegidos. Essa concepção foi explicitada definitivamente na metade do século XX demonstrando a "interdependência entre a ideia de dignidade da pessoa humana e a proteção dos direitos individuais fundamentais que se articula ao nível constitucional desde o início da história do Estado de Direito [...]” (MELLO, 2006, p. 77-78).

No âmbito internacional destaca-se a Declaração Universal dos Direitos do Homem (1948) que em seu artigo $1^{\circ}$ estabelece: “Todos os homens nascem livres e iguais em dignidade e direitos. São dotados de razão e consciência e devem agir em relação uns aos outros com espírito de fraternidade.” E a Declaração Universal do Genoma Humano e dos Direitos Humanos (25 de julho de 1997) estabelece em seu $\operatorname{artigo} 2^{\circ}$ :

a) todos têm o direito por sua dignidade e seus direitos humanos, independentemente de suas características genéticas.

b) Essa dignidade faz com que seja imperativo não reduzir os indivíduos a suas características genéticas e respeitar sua singularidade e diversidade.

Importante também destacar a Introdução aos Princípios de Yogyakarta (2007), documento apresentado no Conselho de Direitos Humanos da ONU que trata sobre a aplicação da legislação internacional de Direitos Humanos em relação à orientação sexual e identidade de gênero que estabelece "o direito ao reconhecimento perante a lei e o direito à privacidade". (DIAS, 2009, p. 71-72). Veja-se o no Princípio 6 de Yogyakarta:

Toda pessoa, independente de sua orientação sexual ou identidade de gênero, tem o direito de desfrutar de privacidade, sem interferência arbitrária ou ilegal, inclusive em relação à sua família, residência e correspondência, assim como o direito à proteção contra ataques ilegais à sua honra e reputação. $\mathrm{O}$ direito à privacidade normalmente inclui a opção de revelar ou não informações relativas à sua orientação sexual ou identidade de gênero, assim como decisões e escolhas relativas a seu próprio corpo e a relações sexuais consensuais e outras relações pessoais. (Grifamos) 
Por ser a sexualidade uma parte integrante da personalidade humana, são considerados Direitos Humanos universais fundamentados na liberdade inerente, dignidade e igualdade para todos os seres humanos. Assim, em 1999 foi aprovada pela WAS (World Association for Sexology), durante o XV Congresso Mundial de Sexologia, a Declaração dos Direitos Sexuais reafirmando que "a sexualidade é um aspecto central do ser humano em toda a vida e abrange sexo, identidade e papeis de gênero, orientação sexual, erotismo, prazer, intimidade e reprodução”.

Sem esquecer, o inciso II, do art. $4^{\circ}$ da Constituição que estabelece que a República Federativa do Brasil rege-se nas suas relações internacionais por princípios e, entre eles, a prevalência dos direitos humanos.

O transexual, como todos os indivíduos, nasce igual em dignidade e direitos, não devendo ser reconhecido somente por suas características genéticas, mas sim respeitado em sua singularidade e diversidade.

A possibilidade de cirurgia para redesignação de sexo é um direito assegurado a qualquer um que pretenda mudar sua condição e se apresentar socialmente como alguém do sexo oposto, representando um importante avanço no respeito à diversidade. Outro aspecto importante é a adequação de seu registro civil a sua verdadeira condição. E consoante explica Dias (2009, p. 239) “(...) o direito à identidade tem assento constitucional. Está inserido na sua norma de maior relevância, que proclama o princípio de respeito à dignidade humana”.

Nessa linha de pensamento, importante esclarecer que o transexual não pretende, em um primeiro momento, adequar sua condição ao mundo jurídico, mas sim encontrar o equilíbrio entre seu corpo e sua mente. No entanto, essa mudança traz consequências jurídicas, já que para essa harmonização estar completa é necessário adequar seu registro civil. Assim explicita Fernandes (2010, p. 46):

\footnotetext{
O transexual busca, acima de tudo, um equilíbrio que possibilite a plena harmonia entre corpo e mente, em uma existência digna de pleno gozo de seus direitos fundamentais e sociais. Esse equilíbrio se dá, em uma primeira dimensão, através da alteração do estado físico do sexual á sua condição psicológica como alguém do sexto oposto. Dessa forma, há de haver uma readequação em uma segunda dimensão, concernente à identidade do indivíduo transexual perante o ordenamento jurídico.
}

Está se falando, então da intimidade e da vida privada de um indivíduo que tem a mesma dignidade e os mesmos direitos do que qualquer outro e que o Estado pretende 
intervir determinando se o transexual deve informa sua condição a terceiros, já que interfere também em suas vidas.

Uma das primeiras referências jurídicas no Brasil sobre o assunto e que estabeleceu parâmetros para a averbação no registro civil da mudança de sexo foi o Recurso Especial no 678.933/ RS julgado no dia 22 de março de 2007 pelo Superior Tribunal de Justiça (STJ). Nesse caso, o Ministério Público do Estado do Rio Grande do Sul interpôs o Recurso Especial para atacar sentença confirmada pelo Tribunal de Justiça (TJ) que permitiu a alteração do registro civil no que diz respeito ao nome e ao sexo do transexual, determinando segredo de justiça e vedando a extração de certidões referentes à situação anterior, a não ser a pedido do interessado ou por requisição judicial.

O recorrente argumentou ser necessária a averbação da condição do recorrido no registro civil por conta de eventuais prejuízos causados a terceiros de boa-fé que se envolvessem com o indivíduo em uma relação emocional ou jurídico-obrigacional. $\mathrm{O}$ Tribunal, por sua vez, explicou que os ditos prejuízos a terceiros eram suposições e sequer se saberia se isso efetivamente aconteceria. A discussão girou, exclusivamente, na necessidade ou não de averbar no registro civil a mudança cirúrgica do sexo. Por fim, o Recurso Especial foi provido determinando a averbação no registro civil de que a alteração do nome e do sexo se deu por determinação judicial. Veja-se parte da argumentação:

[...] Não se pode esconder no registro, sob pena de validarmos agressão à verdade que ele deve preservar que a mudança decorreu de ato judicial, nascida da vontade do autor e que tornou necessário ato cirúrgico complexo. Trata-se de registro imperativo e com essa qualidade é que se não pode impedir que a modificação da natureza sexual fique assentada para o reconhecimento do direito do autor.

Nessa decisão, o STJ explicitou que a omissão da condição do transexual em seu registro civil fere os preceitos da igualdade, da honra e da dignidade entre os indivíduos, considerando o princípio da dignidade acima do direito à privacidade individual. No entanto, entende-se que o que deve ser observado/ponderado é o direito à privacidade do transexual e o direito à informação de terceiros..

Já no ano de 2009, outro Recurso Especial de nº 1.008.398/SP (2007/0273360-5) foi interposto impugnando a decisão do Tribunal de Justiça de São Paulo que indeferiu o pedido de adequação do nome e sexo no registro civil de um indivíduo que realizou a cirurgia de redesignação de sexo. Nesse caso, o recurso foi provido determinando o 
novo registro civil, mas sem que nele conste a averbação que poderá figurar somente nos livros cartorários, contrariando a decisão anterior. Em sua decisão, a relatora do processo argumenta que a averbação da condição de transexual na margem do registro civil exporia o indivíduo a situações vexatórias e humilhantes:

A proposta de afirmação dos direitos humanos no âmbito da sexualidade é, sem dúvida, relevante para superar a lógica de dominação e coerção imposta historicamente à sexualidade humana, e comporta profundas mudanças no tratamento dado às dimensões públicas e privada deste aspecto da vida humana.

O princípio democrático, da universalidade, indivisibilidade, diversidade e laicidade são os princípios de direitos humanos eleitos, para nortear e fundamentar o delineamento e a implementação dos direitos sexuais. (VENTURA, 2007, p. 145).

Um dos fundamentos domésticos para a alteração do registro civil, de acordo com Dias (2009, p. 239-240) são os artigos $6^{\circ}$ e 196 da Constituição que asseguram o direito à saúde entre os direitos sociais, encargo este imposto ao próprio Estado. E continua explicando que saúde é o completo estado de bem-estar físico, psíquico e social, de acordo com a Organização Mundial de Saúde (OMS). Dessa forma, continua a autora (DIAS, 2009, p. 240):

A falta de identidade do transexual provoca desajuste psicológico, não se podendo falar em bem-estar físico, psíquico ou social. Assim, a adequação ao registro é uma garantia à saúde, e a negativa de modificação afronta imperativo constitucional, revelando severa violação aos direitos humanos.

Atualmente, tramita no Supremo Tribunal Federal (STF) o Recurso Extraordinário n. 670.442RG/RS, no qual foi reconhecida a repercussão geral para se discutir a alteração do assento de nascimento, retificação do nome e do gênero sexual de processo oriundo do estado do Rio Grande do Sul.

Com o processo a parte interessada pretende a retificação do registro civil para troca de prenome e sexo no assento de nascimento. Em Primeira Instância o pedido foi julgado parcialmente procedente para a troca do prenome, mas sem a alteração do gênero de feminino para masculino. Em grau de recurso, no ano de 2011, o órgão julgador deu provimento parcial à apelação, determinando a averbação, no assento de nascimento da recorrente, da condição de transexual, ante os princípios da publicidade e da veracidade dos registros públicos. 
Justificou-se que, mesmo com as avançadas técnicas cirúrgicas, os transexuais não são capazes de adquirir todas as características do sexo oposto ao que nasceram não possuindo os órgãos genitais artificialmente constituídos as mesmas características e funcionalidades dos naturais e, principalmente, por ser imutável o aspecto cromossômico.

Ainda, a providência determinada não traria prejuízo algum à recorrente, já que, normalmente, utilizam-se documentos de identidade dos quais não consta o gênero do portador, como carteira de identidade e passaporte.

Ao se pronunciar a respeito do reconhecimento da repercussão geral do assunto, o Ministro do STF Marco Aurélio destacou a competência do Estado com a "tutela da intimidade dos transexuais, mediante a proteção das respectivas escolhas de vida contra o controle público e o estigma social". Ademais, continua o Ministro:

\begin{abstract}
Ressalta-se ofender o princípio da dignidade da pessoa humana impedir que o transexual escolha o próprio sexo, ao argumento da imutabilidade cromossômica ou em razão da presença de certo aparelho genital. Aduz-se a impossibilidade de reduzir o conceito de gênero apenas ao elemento morfológico.
\end{abstract}

O assunto está amadurecendo social e juridicamente, mas ainda é polêmico e até o próprio julgador mostra insegurança ou até um ato falho ao tratar o tema no julgamento. No RE n. 670.442RG/RS a pretensão da parte é trocar o nome de SARA para SANDRO e o gênero de feminino para masculino.

No Primeiro Grau o processo tramitou em segredo de justiça, no entanto, nos despachos disponíveis no site do Tribunal ${ }^{11}$, o juiz tratou Sandro como "a parte autora". Para fazer o relato do percurso do processo do Primeiro para o Segundo Grau o Relator deste inicia se referindo que o apelo foi interposto por SARA/SANDRO. Mais adiante, diz que a parte é um homem que nasceu em um corpo de mulher, e passa a referir-se a ele sempre no sentido masculino: o recorrente, o apelante, o registro dele, ele tem uma companheira e reitera diversas vezes em seu relatório que SANDRO é homem.

O Relator do processo RE n. 670.442RG/RS que reconheceu a repercussão geral do tema indicou Sandro uma vez como "o recorrente" e nas demais vezes que precisou se referir a ele utilizou o termo "parte recorrente". Outro Ministro faz um

11 www.tjrs.jus.br.

ISSN - 2448-3931 | Costa Rica | v. 3 | n. 1 | p. 49-74| jan/jun. 2017 
pronunciamento a respeito do reconhecimento da repercussão geral e refere-se a Sandro, em toda a sua manifestação como "a recorrente" e "a interessada".

O Poder Judiciário como um todo caminha no sentido de que é necessário reconhecer e proteger o individuo em suas escolhas de gênero, mas quando Sara diz que é Sandro, se sente como Sandro e vive como tal é referido pelo sexo biológico e não na forma como ele efetivamente se sente perante a sociedade.

A masculinidade do indivíduo, como bem discorreu o Relator do processo no Segundo Grau Rui Portanova não se prova somente com a existência de um pênis. Nesse sentido, consignam-se algumas de suas palavras:

\footnotetext{
Renovada vênia, a masculinidade de um homem não está restrita aos seus órgãos sexuais.

Um homem não é identificado (ou identificável) apenas pelo pênis.

Pense-se, por exemplo, em alguém que tenha tido ou sofrido um acidente ou uma doença, que tenha resultado em perda do pênis (certos tipos de câncer no pênis, por exemplo, podem levar à isso).

Nem por isso se haverá de pensar que, pela perda do pênis em função do acidente ou da doença, a pessoa deixou de ser homem.

Lembro ainda dos casos polêmicos no esporte, envolvendo a lutadora de judô Edinanci Silva, e a jogadora de vôlei Érika Coimbra.

Ambas foram afastadas do esporte durante algum tempo, e tiveram que passar por tratamento cirúrgico e hormonal, porque os testes apontavam que elas eram homens (e os testes conduzidos no âmbito do esporte são rígidos e profundos).

Nenhuma delas tinha pênis.

Para além disso, o pênis está ligado à potência e à fertilidade do homem.

Mas a masculinidade do homem também não está na sua potência ou na sua fertilidade - pois o impotente e o infértil seguem sendo, e considerados como sendo, homens.

Na realidade, o pênis, por si só, não pode servir como critério exclusivo de identificação da masculinidade.

Ser homem é mais do que ter um pênis.

E não é por ter ou não ter um pênis, que alguém vai ser ou deixar de ser um homem.

Para aferir a masculinidade, um critério muito mais seguro é a identificação social da pessoa em seu meio.
}

Argumentos contrários a troca de prenome e gênero no assento de registro civil podem ser encontrados no seguinte processo: em 2013 o Tribunal de Justiça do Rio Grande do Sul julgou a apelação (proc. n.70052872868) do Ministério Público contra uma decisão de Primeiro Grau em que se autorizou a mudança do prenome e do sexo em razão da transexualidade do indivíduo. Como argumento o Parquet defendeu que a situação não se coaduna com a preservação da dignidade da pessoa humana, uma vez que não existe dispositivo legal que autorize tal medida. 
Ao contrário, sustentou que a mudança de sexo na certidão de nascimento constitui crime de falsidade ideológica, não perdendo a tipicidade, ilegalidade e culpabilidade apenas porque o Poder Judiciário assim permitiu. Asseverou que a manutenção da decisão poderia gerar uma série de fraudes como, por exemplo, a aposentadoria com tempo de contribuição menor do que o exigido para os homens. Requereu a extinção do processo por impossibilidade jurídica do pedido, no entanto foi julgado improcedente o recurso.

\section{CONCLUSÃO}

O Direito é um conjunto de normas que regem a vida em sociedade, mas, principalmente, representa os valores de determinada comunidade em um espaço de tempo. E é nesse contex to que devemos pensar o direito à intimidade do transexual.

Verifica-se, diante da legislação apresentada, uma permanente evolução e desenvolvimento dos direitos fundamentais como Direitos Humanos positivados, mas também valores intrínsecos que são considerados, mesmo não sendo explicitados.

$\mathrm{O}$ respeito a vida privada e a intimidade do transexual encontra suporte na legislação internacional e na doméstica, representado pelo respeito à dignidade da pessoa humana.

Mas antes de o leitor formar seu entendimento a respeito do assunto recomendase a leitura da doutrina apresentada, a legislação nacional e internacional e as decisões dos tribunais brasileiros em conjunto com os dados sobre a violência contra os transexuais no Brasil.

Segundo os dados da ONG TGEU (Transgender Europe), “a comunidade transexual é a que mais sofre violência no país. O Brasil ainda é considerado o país que mais mata transexuais no mundo: a expectativa de vida dessas pessoas é de 35 anos" (2016).

Concorda-se com a manifestação do Desembargador Rui Portanova, ao explicar que a masculinidade de uma pessoa não se prova somente com seus órgãos genitais, mas com a identificação social da pessoa em seu meio. De toda sorte, nos casos de transexuais que passaram pela cirurgia de redesignação de sexo, cabe a eles o poder de decisão sobre informar o companheiro ou cônjuge sobre essa condição. A informação

$\underline{\underline{\text { ISSN - 2448-3931 | Costa Rica | v. } 3 \text { | n. } 1 \text { | p. 49-74| jan/jun. } 2017}}$ 
realmente importante é sobre a impossibilidade de gerar filhos quando há uma expectativa de formação de uma família incluindo a prole.

A informação deve ficar restrita aos livros cartorários e será disponibilizada a requerimento da parte ou por determinação judicial. Essa é a forma adequada de tratar o assunto e não violar a intimidade e a vida privada do transexual, já que consignar essa condição no registro civil representa uma violação a dignidade da pessoa humana.

O transexual deve ser reconhecido pela forma como ele escolheu se apresentar socialmente. E passar por uma transformação tão dolorosa não só fisicamente, mas também emocionalmente como deve ser a cirurgia de redesignação de sexo, só reforça o entendimento de que aquele indivíduo nasceu no corpo errado e seu desejo deve ser respeitado. Como dito no início do artigo, deve-se viver do presente.

\section{REFERÊNCIAS}

BITTAR. Hermenêutica e constituição: a dignidade da pessoa humana como legado à pós-modernidade. In: ALMEIDA FILHO, Agassiz; MELGARÉ, Plínio (Org.).

Dignidade da pessoa humana: fundamentos e critérios interpretativos. São Paulo: Malheiros, p. 239-266, 2010.

BITTAR, Carlos Alberto; ALMEIDA, Guilherme Assis de. Curso de filosofia do direito. 10. ed. rev. aum. São Paulo: Atlas, 2012.

BRASIL. Presidência da República. Constituição da República Federativa do Brasil, de 5 de outubro de 1988. Disponível em:

$<$ http://www.planalto.gov.br/ccivil_03/constituicao/constituicao.htm>. Acesso em 20 fev. 2017.

BRASIL. Lei n. 10.406 de 10 de janeiro de 2002. Institui o Código Civil. Disponível em: < http://www.planalto.gov.br/ccivil_03/leis/2002/L10406.htm>. Acesso em 20 fev. 2017.

BRASIL. Superior Tribunal de Justiça. Resp n ${ }^{\circ}$ 1.008.398/SP. $3^{\text {a }}$ T. Relatora Ministra Nancy Andrighi, julgado em 15/10/2009. Disponível em:

$<\mathrm{https}$ ://ww2.stj.jus.br/processo/monocraticas/decisoes/?num_registro=200702733605\& dt_publicacao=01/09/2009> Acesso em: 27 fev. 2017.

BRASIL. Superior Tribunal de Justiça. Recurso Especial n ${ }^{\circ} 678.933 / R S 3^{a}$ T. Relator Ministro Carlos Alberto Menezes Direito, julgado em 22/03/2007. Disponível em: $<$ https://ww2.stj.jus.br/processo/revista/inteiroteor/?num_registro $=200400980835 \&$ dt_publicacao=21/05/2007> Acesso em: 27 fev. 2017.

BRASIL. Supremo Tribunal Federal Recurso Extraordinário n. 670.442RG/RS, relator Ministro Dias Toffoli. Disponível 
em: $<$ http://www.stf.jus.br/portal/jurisprudenciarepercussao/verAndamentoProcesso.asp ?incidente $=4192182 \&$ numeroProcesso $=670422 \&$ classeProcesso $=$ RE $\&$ numeroTema $=76$ 1\#>.Acesso em: 01 mar. 2017.

BRASIL. Tribunal de Justiça do Rio Grande do Sul apelação (proc. n.70052872868) $8^{\text {a }}$ CC. Relator Ministro Alzir Felippe Schmitz, julgado em 04/04/2013. Disponível em: $<$ http://www.tjrs.jus.br/site_php/consulta/consulta_acordaos.php?Numero_Processo $=70052872868 \&$ code $=0454 \&$ entrancia $=2 \& i d \_$comarca $=700 \&$ nomecomarca $=$ Tribunal $\%$ 20de\%20Justi\%E7a\&orgao=TRIBUNAL\%20DE\%20JUSTI\%C7A\%20\%208.\%20CAMARA\%20CIVEL> Acesso em: 27 fev. 2017.

COMPARTO, Fábio Konder. A afirmação histórica dos direitos humanos. 7 ed. rev. e atual. São Paulo: Saraiva, 2010.

DECLARAÇÃO Universal do Genoma Humano e dos Direitos Humanos. Disponível em: <http://www.ghente.org/doc_juridicos/dechumana.htm> Acesso em: 20 fev. 2017.

DECLARAÇÃO Universal dos Direitos do Homem

$<$ http://www.ghente.org/doc_juridicos/decdirhumanos.htm>. Acesso em: 20 fev. 2017. DECLARAÇÃO dos Direitos Sexuais< http://spsc.pt/wp-

content/uploads/2017/01/DIREITOS-SEXUAIS-WAS.pdf>. Acesso em: 28 fev. 2017.

DIAS, Maria Berenice. União homoafetiva: o preconceito \& a justiça. 4 ed. rev. e atual. São Paulo: Editora Revista dos Tribunais, 2009.

FACHIN, Luiz Edson; RUZYK, Carlos Eduardo Pianovski. Direitos fundamentais, dignidade da pessoa humana e o novo Código Civil: uma análise crítica. In: COUTINHO, Adalcy Rachid et al.; SARLET, Ingo Wolfgang (Org.). Constituição, direitos fundamentais e direito privado. 3 ed. rev. ampl. Porto Alegre: Livraria do Advogado, p. 97-110, 2010.

FACCHINI NETO, Eugênio. Reflexões histórico-evolutivas sobre a constitucionalização do direito privado. In: SARLET, Ingo Wolfgang. (Org).

Constituição, direitos fundamentais e direito privado. 3. ed. rev. ampl. Porto Alegre: Livraria do Advogado, p. 37-75, 2010.

FERNANDES, Eric Baracho Dore. Os direitos da personalidade e a problemática dos transexuais. Revista de Direito dos monitores da Universidade Federal Fluminense, n. 7, p. 31-72, abr 2010. Disponível em:

<http://www.rdm.uff.br/index.php/rdm/article/view/133/80>. Acesso em: 03 mar. 2017.

GOMES, Sérgio Alves. Hermenêutica constitucional: um contributo à construção do Estado Democrático de Direito. 3. reimp. Curitiba: Juruá, [2008] 2011.

INNOVARE. A violência contra transexuais no Brasil. 2016. Disponível em: $<$ http://www.innovarepesquisa.com.br/blog/violencia-contra-transexuais-brasil/ $>$. Acesso em: 01 mar. 2017.

MELLO, Cláudio Ari. Contribuição para uma teoria híbrida dos direitos de personalidade. In: MELLO, Cláudio Ari et al.; SARLET, Ingo Wolfgang (Org.). O

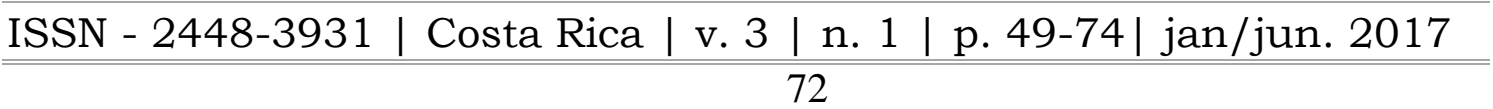


novo Código Civil e a Constituição. 2. ed. rev. e ampl. Porto Alegre: Livraria do Advogado, 2006. p. 69-100.

MORAES, José Bolzan de. SANTIN, Janaína Rigo. Dignidade da pessoa humana: fundamentos e critérios interpretativos. Agassiz Almeida Filho e Plínio Melgaré (org.) Constituição e direitos humanos. Ou: só é possível dignidade na constituição. SP: Malheiros, p. 422-447, 2010.

MORAES, Maria Celina Bodin de. O conceito de dignidade humana: substrato axiológico e conteúdo normativo. In: COUTINHO, Adalcy Rachid et al.; SARLET, Ingo Wolfgang (Org.). Constituição, direitos fundamentais e direito privado. 3. ed. rev. ampl. Porto Alegre: Livraria do Advogado, p. 111-144, 2010.

A constitucionalização do direito civil e seus efeitos sobre a responsabilidade civil. Direito, Estado e Sociedade, v. 9, n. 29, p. 233 a 258, jul./dez. 2006.

NIPPERDEY, Hans Carl. Direitos fundamentais e direito privado. In: DURIG, Gunter et al.; HECK, Luís Antônio. (Org.). Direitos fundamentais e direito privado: textos clássicos. Porto Alegre: Sergio Antonio Fabrisp. 51-70, 2011.

PORTUGAL. Tribunal Constitucional. Acórdão n 90-105-2. Disponível em:

$<$ http://www.tribunalconstitucional.pt>/(mediante cadastro gratuito). Acesso em: 06 jan. 2017.

PRINCIPIOS_de_yogyakarta.Disponível em:

$<$ http://www.clam.org.br/uploads/conteudo/principios_de_yogyakarta.pdf $>$. Acesso em 23 fev. 2017.

SARLET, Ingo Wolfgang. A influência dos direitos fundamentais no direito privado: o caso brasileiro. In: MONTEIRO, António Pinto; NEUNER, Jörg; SARLET, Ingo Wolfgang (Org.). Direitos Fundamentais e Direito Privado: uma perspectiva de direito comparado. Coimbra: Almedina, p. 111-144, 2007.

\section{.Dignidade da pessoa humana e direitos fundamentais na Constituição}

Federal de 1988. 9. ed. Porto Alegre: Livraria do Advogado Editora, 2012.

As dimensões da dignidade da pessoa humana: construindo uma compreensão jurídico-constitucional necessária e possível. In: SARLET, Ingo Wolfgang (Org.).

Dimensões da dignidade: ensaios de filosofia do direito e direito constitucional. 2.ed. rev. ampl. Porto Alegre: Livraria do Advogado, 2009.

Neoconstitucionalismo e influência dos direitos fundamentais no direito privado: algumas notas sobre a evolução brasileira. In: COUTINHO, Adalcy Rachid et al.; SARLET, Ingo Wolfgang (Org.). Constituição, direitos fundamentais e direito privado. 3. ed. rev. ampl. Porto Alegre: Livraria do Advogado, p. 13-36, 2010.

Os direitos fundamentais sociais, o direito a uma vida digna (mínimo existencial) e o direito privado: apontamentos sobre a possível eficácia dos direitos sociais nas relações entre particulares. In: ALMEIDA FILHO, Agassiz; MELGARÉ, 
Plínio (Org.). Dignidade da pessoa humana: fundamentos e critérios interpretativos. São Paulo: Malheiros, p. 375-421, 2010a.

VENTURA, Miriam. Transexualidade: algumas reflexões jurídicas sobre a autonomia corporal e autodeterminação da identidade sexual. Em defesa dos direitos sexuais/ org. Roger Raupp Rios; José Reinaldo de Lima Lopes ...[et al.] - Porto Alegre: Livraria do Advogado Editora,. p. 141-167, 2007 